\title{
The Association Between Organizational Characteristics and Strategic Information Systems Planning: A Study of U.S. Hospitals
}

\author{
Soumya Upadhyay, PhD \\ University of Nevada at Las Vegas, USA \\ William Opoku-Agyeman, PhD \\ University of Alabama at Birmingham, USA \\ Deirdre McCaughey, PhD \\ University of Calgary, Canada \\ Darrell E. Burke, PhD \\ University of Alabama at Birmingham, USA
}

Doi: 10.19044/esj.2017.v13n36p36 URL:http://dx.doi.org/10.19044/esj.2017.v13n36p36

\begin{abstract}
Despite the potential of Strategic Information System Planning (SISP) to reduce cost and improve quality, hospitals have been slow to have strategic plans on Information Systems. Our objective was to explore which organizational characteristics influence SISP in healthcare. Data on Information Systems plans from the HIMSS analytics database was combined with organizational characteristics data from the American Hospital Association. Logistic regression analyses on a sample of 2,495 hospitals revealed that hospitals with system membership and for profit status had a greater likelihood of selecting 'computerized medical records' $(\mathrm{OR}=1.88, \mathrm{OR}=6.60$ respectively, $p<0.05)$, 'decreasing medical errors' $(\mathrm{OR}=7.02, p<0.05)$, 'resolving integration issues' $(\mathrm{OR}=1.36, \mathrm{OR}=0.15$ respectively, $\quad p<0.05)$, 'migrating towards a paperless environment $(\mathrm{OR}=1.66, \mathrm{OR}=8.28$ respectively, $p<0.05)$, and 'reducing the number of software vendors' $(\mathrm{OR}=1.78, \mathrm{OR}=0.23$ respectively, $p<0.05)$ as their Information System plans. System membership and ownership status are associated with SISP. An understanding of the hospital characteristics that may impact Strategic Information Systems Planning, managers would assist managers in making informed decisions about planning and implementing Information Systems at their hospitals.
\end{abstract}

Keywords: SISP; U.S. hospitals; information systems 


\section{Introduction}

Strategic Information Systems Planning (SISP) has been gaining interest among healthcare practitioners and researchers because of the better quality and financial outcomes that healthcare information technology helps to achieve (Amrollahi, Ghapanchi, \& Talaei-Khoei, 2013; Hoque, Hossin, \& Khan, 2016). It is a management approach to increase efficiency, reduce costs and improve quality through alignment with organizational strategy. Strategic Information Systems Planning (SISP) is defined as the process of identifying information systems that will assist a business in executing its organizational plans and accomplishing its business goals (Lee, Ghapanchi, Talaei-Khoei, \& Ray, 2015; Winter et al., 2000). Strategic information systems are designed to assist information systems planners in aligning their strategies with those of the organization (Agarwal, Gao, DesRoches, \& Jha, 2010).

The extant literature has discussed how information systems improve operational efficiency, manage healthcare costs, enhance the quality of care, ensure patient safety and enable integrity and security of patients' information (Agarwal et al., 2010; Hibbard \& Greene, 2013; Pai \& Huang, 2011). In conjunction with this, factors like organizational characteristics, have been shown to have an association with the adoption of healthcare information systems and health information technology (Menachemi, Shin, Ford, \& Yu, 2011). However, there is a dearth of studies that have focused on the organizational antecedents of SISP in healthcare organizations.

Therefore, the purpose of this study is to fill this gap by specifically examining the relationship between organizational characteristics and SISP through the conceptual lens of contingency theory. This paper presents a key contribution to researchers and practitioners in that, it examines how organizational characteristics can promote or impede the adoption of information systems that are instrumental in achieving better quality at reduced costs. In addition, policy makers will also be able to identify important factors that promote or inhibit the adoption of information systems.

\section{Background and Conceptual Framework}

Healthcare organizations make large investments in information systems (IS) to make positive strategic impact on organizational performance such as metrics of financial and quality outcomes (Ford, Menachemi, Huerta, $\& \mathrm{Yu}, 2010)$. A recent study in this line of research explored the background and trend of research into SISP in the healthcare industry and found that it facilitates educated decisions to achieve an organization's goals and objectives (Lee et al., 2015). Several studies have shown that information systems can lead to improved quality by decreasing medical errors and 
improving efficiency by going paperless, moving to computerized patient records and integrating information systems (Bowman, 2013; Buntin, Burke, Hoaglin, \& Blumenthal, 2011; Lammers, Adler-Milstein, \& Kocher, 2014; Pham et al., 2012). Examples of integrating information systems would be a direct communication between laboratory and pharmacy systems or an electronic linkage between different parts of the medication systems such as prescribing, dispensing, and administering (Chaudhry et al., 2006). Hospitals in the Chaudhry et al. (2006) study intended to achieve these objectives as part of their strategic plans regarding information systems.

However, the healthcare industry lags behind industries such as financial institutions, enterprise and other private industries in adopting IS planning (Agarwal et al., 2010). The complex nature of the industry and the existence of multiple stakeholders such as providers, payers, hospitals and patients; makes it difficult for SISP to be a part of the overall organizational strategic orientation (Sittig \& Singh, 2010). Furthermore, the regulatory requirements under the Health Information Technology for Economic and Clinical Health Act of 2009 include information security, efficient means for sharing information, and accomplishment of quality targets ("HITECH Act", 2009). To deal with these regulatory pressures, it is vital that hospitals engage in actions that strategically plan their information systems.

Contingency theory is based on the important concept of 'fit' and posits that an organization with a better fit with its external environment would perform better and its success would depend on adopting appropriate level of structural variables to fit with contingencies in the situation (Donaldson, 2001). Hospitals try to fit themselves with contingent needs of the external environment. For example, based on contingency theory, research has found that in order to fit with the external environment, hospitals allow more physicians to be involved in the management of hospitals (Bode \& Maerker, 2014). In addition, recent research has shown that for a better fit with the environment and to allow organizational innovation, the size of board of directors should be adequate (Zona, Zattoni, \& Minichilli, 2013). In our study, we use contingency theory to examine the organizational characteristics that can help a hospital achieve a better fit with the environment in terms of Strategic Information Systems Planning.

Contingency theorists have suggested that organizations are more successful when their structures fit with their technologies they adopt (Fisher, 1998), and organizations should attempt to maximize the match between their structure and technologies (Otley, 1980). Organizational characteristics such as size, system membership, teaching status, location, and ownership form important components of a hospital's structure (Holup, Dobbs, Meng, \& Hyer, 2014). Hospital management may not have full control over changing the organization's characteristics to adopt their 
structures to fit their technologies. However, knowledge of how a hospital's characteristics might influence SISP may facilitate information systems adoption. As contingency theory contends, understanding the relationship between organizational characteristics and SISP can help in fostering proper alignment of structure and technology.

Contingency theory holds that better performance is realized when there is a good 'fit' between factors, for instance, a congruency between organizational factors and various characteristics of technology (Drazin $\&$ Van de Ven , 1985). From this perspective, we can examine extant literature that illustrates how hospitals with specific organizational characteristics may facilitate or impede the adoption of information systems. Previous literature suggests that small, rural, and non-teaching hospitals are slow in the adoption of information technology and achieving a nationwide health information technology may require efforts targeted at such hospitals (DesRoches et al., 2013). Factors such as size and ownership status, appear to be more influential than market factors when it comes to hospital decisions in the adoption of strategic information systems (Abramson et al., 2012; Houser \& Johnson, 2008; Zhang et al., 2013). Prior literature discusses the influence of organizational characteristics on adoption of information systems. However, to achieve a good performance through a fit between technology adoption and organizational characteristics, strategic planning is essential (Hoque, Hossin, \& Khan, 2016).

Based on previous research findings on the adoption of information technology, our paper expects to find similar relationships between specific hospital characteristics and SISP. We hypothesize that organizational characteristics (as factors representing structure) influence strategic information system planning and therefore, we examine the association between size, system membership, teaching status, location, and ownership with SISP (See Figure 1). Against the aforementioned background and the conceptual framework, we developed the following exploratory research hypothesis:

H 1: Organizational characteristics such as size, system membership, teaching status, location, and ownership status are associated with Strategic Information System Planning (SISP). 
Figure 1: Conceptual Framework about the Impact of Organizational Characetristics on Strategic Information Systems Planning

\begin{tabular}{|l|}
\hline Organizational \\
Characteristics
\end{tabular}$\longrightarrow \begin{gathered}\text { Strategic } \\
\text { Information } \\
\text { Systems Planning }\end{gathered}$

\section{Methods}

\section{Data and Sample}

Our study explores the relationship between organizational characteristics and Strategic Information Systems Planning (SISP). The study utilizes a cross-sectional design that draws data from three sources including the 2014 Healthcare Information and Management Systems Society (HIMSS) Analytics Database, the 2014 Area Resource File (ARF) and the 2014 American Hospital Association (AHA) Annual Survey for Hospitals. In our study, we focus upon non-federal general acute care hospitals. The HIMSS Analytics Database (2014) contains self-reported data from U.S. hospitals including data on information systems plans. The ARF dataset and AHA Annual Survey provide data regarding organizational characteristics of hospitals. Datasets were linked together using Medicare identification numbers. Our final analytic sample contained 2,495 hospital observations.

\section{Measures}

Dependent variables: As our outcome variables, we use the various elements of strategic information systems planning in the HIMSS analytics database. Hospitals report different strategic information system plans that they have adopted and/ or implemented to improve quality and efficiency. The strategic information systems plans reported in the survey are: i) moving to computerized patient records, ii) decreasing medical errors, iii) integration issues, iv) migrating to a paperless environment and v) reducing the number of software vendors. We assigned a value of 1 to each plan if it was selected, and 0 if the plan was not selected. Next, the responses were summed to create a score that showed the total number of plans selected by each hospital, therefore equating to the level of strategic information systems planning (SISP) at each hospital (Holup et al., 2014). The scores ranged from 0 indicating the lowest level of SISP to 5 indicating the highest level of SISP. In total, we have six dependent variables, the six strategic information 
system plans, and a summated score for all strategic information system plans.

Independent variables: 'Organizational factors' were operationalized by using organizational characteristics that are associated with the adoption of new technology among hospitals and healthcare systems (Najaftorkaman, Ghapanchi, Talaei- Khoei, \& Ray, 2015). As measures of organizational characteristics, we employ the following hospital characteristics: i) size (measured as total number of beds), ii) system membership (no/yes), iii) teaching status (no/ yes), iv) location (rural/urban), and v) ownership status (nonprofit, for-profit, or public) as predictive variables of strategic information system plans. Size was a continuous variable measured by the total number of beds. System membership was dichotomized as hospitals that were not affiliated to a system (coded as 0), and hospitals that belonged to a system (coded as 1). Teaching status was dichotomized into nonteaching hospital (coded as 0) and teaching hospital (coded as 1). Nonteaching hospitals were used as the reference category. Location was of two types - rural (less than 2500 population) and urban (greater than 2500 population). Rural hospitals were used as the reference category. Finally, under ownership status, dummy variables were created for for-profit and public hospitals. Not-for profit hospitals were the reference category. Hospitals that did not belong to a system were used as the reference category.

\section{Analytic Approach}

Descriptive statistics were used to describe the data for 2,495 hospitals. Bivariate statistics were used to describe variations in the level of strategic information systems plan across various organizational characteristics. Independent sample t-test and chi square tests were used to examine the differences in mean level of Strategic Information Systems Planning (SISP) across size, system membership, teaching status, location, and ownership status.

To account for the binary nature of our first six dependent variables (whether each plan was selected or not), logistic regression was employed as our primary method of analysis. For our seventh dependent variable, the summated score, we used ordinal logistics regression to assess the relationship between organizational characteristics and the summated score of the information systems plans. Ordinal logistics regression was used because our dependent variable was count data with equal intervals. All analyses were performed using Stata version 13 (StataCorp LP, 2015).

\section{Results}

Descriptive characteristics of 2,495 hospitals are displayed in Table 
1. On average, the bed size of hospitals considered in the study is approximately 200 beds $(\mathrm{SD}=208)$. Overall, the majority of hospitals do not belong to a health system (70\%) and are not affiliated with a teaching status $(93 \%)$. Hospitals are located primarily in urban areas (82.6\%) and most are not-profit (69\%). With regard to SISP, overall, 2,341 (94\%) hospitals report

Table 1. Descriptive Statistics of Level of Strategic Information Systems Planning (SISP), Organizational Characteristics, and Information Systems Plans $(\mathrm{N}=2,495)$

\begin{tabular}{|c|c|}
\hline Variables & Mean (SD) \\
\hline $\begin{array}{l}\text { Level of Strategic Information Systems Plan (measured } \\
\text { by total number of Information Systems Strategic Plan) }\end{array}$ & $4.1(1.18)$ \\
\hline \multirow[t]{2}{*}{ Bed size } & $200.9(208.18)$ \\
\hline & Frequency $(\%)$ \\
\hline \multicolumn{2}{|l|}{ System Membership } \\
\hline Yes & 742(29.74) \\
\hline No & $1,753(70.26)$ \\
\hline \multicolumn{2}{|l|}{ Teaching Status } \\
\hline Yes & $181(7.25)$ \\
\hline No & $2,314(92.75)$ \\
\hline \multicolumn{2}{|l|}{ Location } \\
\hline Urban & $2,061(82.61)$ \\
\hline Rural & $434(17.39)$ \\
\hline \multicolumn{2}{|l|}{ Ownership Status } \\
\hline Nonprofit & $1,730(69.34)$ \\
\hline For-profit & $351(14.07)$ \\
\hline Public & $414(16.59)$ \\
\hline \multicolumn{2}{|l|}{ Strategic Information Systems Plans } \\
\hline \multicolumn{2}{|l|}{ Computerized patient record } \\
\hline Yes & $2,341(93.95)$ \\
\hline No & $151(6.05)$ \\
\hline \multicolumn{2}{|l|}{ Decreasing medical errors } \\
\hline Yes & $368(14.75)$ \\
\hline No & $2,127(85.25)$ \\
\hline \multicolumn{2}{|l|}{ Integration issues } \\
\hline Yes & $1,854(74.31)$ \\
\hline No & $641(25.69)$ \\
\hline \multicolumn{2}{|l|}{ Migrating toward a paperless environment } \\
\hline Yes & $2,256(90.42)$ \\
\hline No & $239(9.58)$ \\
\hline \multicolumn{2}{|l|}{ Reducing the number of software vendors } \\
\hline Yes & $1,593(63.85)$ \\
\hline No & $902(36.15)$ \\
\hline
\end{tabular}


'computerized patient record', 368 (15\%) report 'decreasing medical errors', $1,854(74 \%)$ report 'resolving integration issues', 2,256 (90\%) report 'migrating towards a paperless environment', and 1,593 (64\%) pursue 'reducing the number of software vendors' as their information systems (IS) plans. The mean level of SISP (represented by the summated score of all Strategic Information System Plans) is $4.1(\mathrm{SD}=1.18)$ out of a maximum of 5 .

Table 2 summarizes bivariate statistics and shows that there is a significant difference between the hospitals in our sample that belong to a healthcare system $(M=3.94, S D=1.29)$ and those that do not $(M=4.13$, $\mathrm{SD}=1.12)$. There is also a significant difference across hospitals in our sample that are non-profit $(\mathrm{M}=4.16, \mathrm{SD}=1.18)$, for profit $(\mathrm{M}=3.72, \mathrm{SD}=0.98)$ and public $(\mathrm{M}=4.04, \mathrm{SD}=1.26)$.

Table 2. Independent Sample T-test between Organizational Characteristics and Level of Strategic Information Systems Planning (SISP) $(\mathrm{N}=2,495)$

Level of Strategic Information Systems Plan (measured by total number of Information

Systems Strategic Plan)

Mean (SD) P value

System Membership

Yes

No

$4.13(1.12)$

0.001

Teaching Status

Yes

No

$3.99(1.36)$

Location

Urban

Rural

4.07 (1.18)

0.466

Ownership Status

Nonprofit

$4.16(1.18)$

For-profit

$3.72(.98)$

0.000

Public

4.04 (1.26)

Table 3 presents the association between organizational characteristics and various information system plans in support of hypothesis 1. Bed size is significantly associated with selecting 'resolving integration issues' $(\mathrm{OR}=0.99)$ as a SISP. Hospitals with system membership have significantly higher odds of selecting 'computerized patient records' $(\mathrm{OR}=1.88)$, 'resolving integration issues' $(\mathrm{OR}=1.32)$, 'migrating towards paperless environment' $(\mathrm{OR}=1.66)$ and 'reducing the number of software 
vendors' $(\mathrm{OR}=1.76)$ as their strategic information system plans as compared to the hospitals that do not belong to a system. Overall, hospitals that belong to a healthcare system have a significantly higher level of SISP as compared to their non-system counterparts. Hospitals that have a teaching status have significantly lower odds $(\mathrm{OR}=0.42)$ of choosing computerized patient records as compared to non-teaching hospitals.

On the other hand, teaching status is not significantly associated with other information system plans. Urban hospitals had significantly lower odds $(\mathrm{OR}=0.58)$ of selecting 'migrating towards a paperless environment' as their SISP as compared to rural hospitals. However, hospital location does not show any significant association with other information system plans. Ownership status is significantly related to all five strategic information systems plans. For profit hospitals have higher odds of selecting 'computerized patient records' $(\mathrm{OR}=6.61)$, 'decreasing medical errors' $(\mathrm{OR}=7.03)$ and 'migrating towards a paperless environment' $(\mathrm{OR}=8.28)$ as their information system plans as compared to non-profit hospitals. However, for profit hospitals have lesser odds of choosing 'resolving integration issues' $(\mathrm{OR}=0.15)$ and 'reducing the number of software vendors' $(\mathrm{OR}=0.23)$ as their SISP as compared to non-profit hospitals. In general, hospitals that belong to a system and have a for-profit status have a greater likelihood of selecting 'computerized patient record' and 'migrating towards a paperless environment'. They also have a lower likelihood of choosing 'integration issues' and 'reducing the number of software vendors' as their SISP. Among organizational characteristics, system membership and ownership status are found to have more significant associations with strategic information system planning than teaching status and location of hospitals.

Table 3. Association between Organizational Characteristics and Strategic Information System Plans $(\mathrm{N}=2,495)$

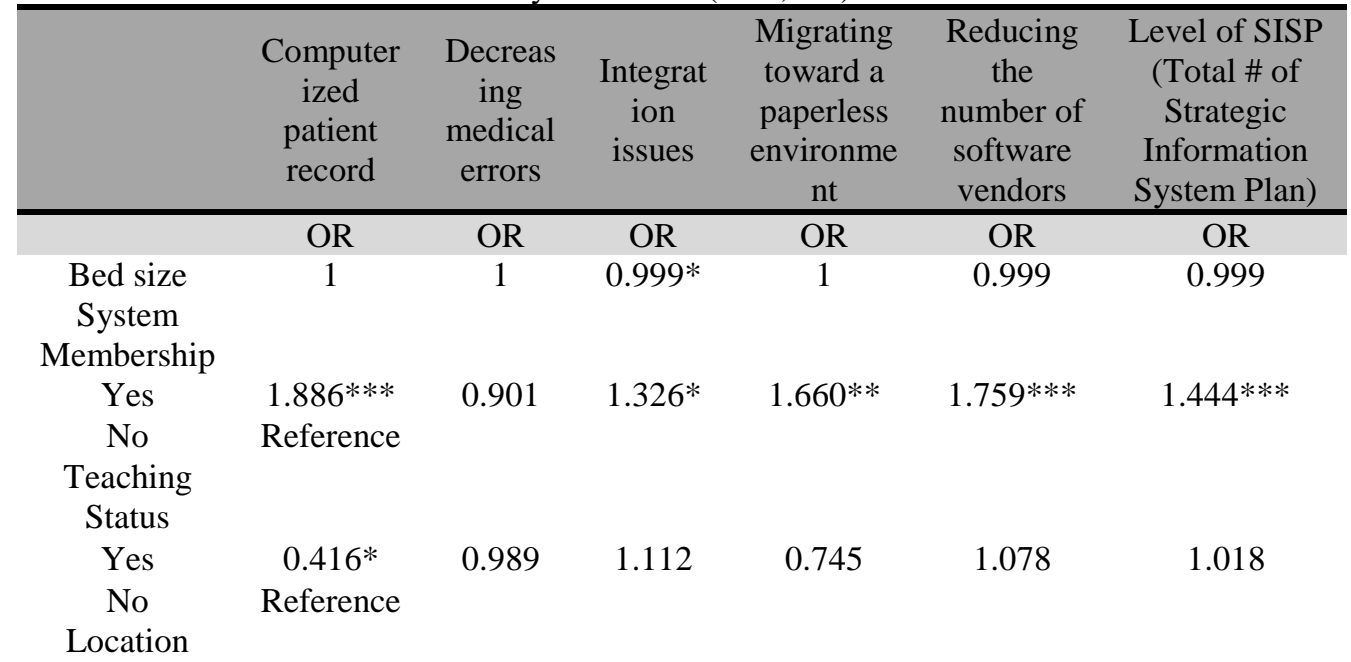




\begin{tabular}{|c|c|c|c|c|c|c|}
\hline $\begin{array}{c}\text { Urban } \\
\text { Rural } \\
\text { Ownership } \\
\text { Status }\end{array}$ & $\begin{array}{c}0.821 \\
\text { Reference }\end{array}$ & 0.991 & 1.161 & $0.578^{*}$ & 1.161 & 1.036 \\
\hline For-profit & $6.605 * *$ & $\begin{array}{c}7.028 * * \\
*\end{array}$ & $\begin{array}{c}0.153 * * \\
*\end{array}$ & $8.279 * * *$ & $0.226 * * *$ & 0.4 \\
\hline $\begin{array}{c}\text { Public } \\
\text { Nonprofit }\end{array}$ & $\begin{array}{c}0.77 \\
\text { Reference }\end{array}$ & 1.027 & 0.942 & 1.269 & 0.846 & 0.926 \\
\hline
\end{tabular}

\section{Discussion}

Using contingency theory as our framework, the purpose of our study was to examine the relationship between organizational structures in the healthcare industry with externally-driven environmental/situational factors. Using organizational characteristics (size, system membership, teaching status, location, and ownership) as a proxy for organizational structure and SISP as a proxy for environment, we tested the relationship between structure and environment. Our major finding in this study was that some organizational characteristics have an association with elements of Strategic Information Systems Planning. Our results highlight numerous organizational characteristics that serve as key SISP factors, thereby supporting contingency theory as a means to show a relationship between structure and environment.

First, for-profit hospitals were more likely to be moving towards more complex IS planning through computerized patient records, decreasing medical errors, migrating towards a paperless environment and reducing the number of software vendors as part of their SISP. It is salutary to note that our findings are consistent with previous studies that found that for-profit hospitals were more likely to exchange data internally possibly leading them to adopt sophisticated health information systems (Miller \& Tucker, 2014). In addition, for profit hospitals have to employ more robust strategies to reduce costs given the cuts in reimbursements and improve quality to potentially remain profitable (White $\& \mathrm{Wu}, 2014$ ). Such a strategy could be planning and adoption of health information systems. With respect to public versus private hospitals, while other studies have found that public hospitals are ahead of private hospitals in adoption of information systems, our study found no significant difference between public and for-profit hospitals as far as having strategic information systems plans (Houser \& Johnson, 2008).

Next, hospitals that have system membership were more likely to be moving towards greater SISP through computerized patient records, resolving integration issues, migrating towards a paperless environment and reducing the number of software vendors. Our findings are similar to those from a prior study that found that hospitals belonging to a system, 
demonstrate greater emphasis towards achieving the overall system objectives that are pertinent to information system integration (Diana, Harle, Huerta, Ford, \& Menachemi, 2014). This may occur because healthcare systems' affiliates generally share their IT infrastructure and software. The decision of moving towards a higher level of SISP by the system may require all individual affiliates to embrace information systems planning especially because they have a common IT infrastructure.

With respect to teaching status, teaching hospitals had a higher level of SISP as compared to non teaching hospitals. Previous research supports our finding, in that; teaching hospitals rapidly adopt Electronic Health Records especially given the impact of the meaningful use component within the HITECH act (DesRoches et al., 2013). However, our study also found that hospitals with a teaching status were less likely to be moving towards one information systems plan, the computerized patient records. A possible explanation is that computerized patient records are more focused towards a reduction in medication errors (Radley et al., 2013). While it is important to strategically plan computerized patient records as a component of information systems, teaching hospitals may have a priority to reduce medical errors, which is a different information systems plan.

Findings from our study were not consistent with prior research because we found that teaching hospitals and urban hospitals are less likely to have certain information systems plans than their counterparts. This is probably because of the cuts in reimbursement to hospitals against the backdrop of the Affordable Care Act (PPACA, 2010). A reduction in reimbursements would limit technological resources such as information systems at hospitals. An alternative explanation would be that teaching and urban hospitals already have information system capabilities and therefore do not see the need for further information systems adoption. Recent studies have identified additional factors as important mediators of information systems adoption. For example, hospitals with telehealth technology and integration tend to be driven by state polices related to reimbursement and the need to address access to care barriers in their communities (AdlerMilstein, Kvedar, \& Bates, 2014). It is plausible that similar factors influenced SISP in our study and account for the mixed findings across studies.

We also found that there was no difference in having strategic information system plans based on hospital location. The total number of IS plans selected was not significantly associated with any of the organizational characteristics that we considered, except system membership. Hospitals with system membership were more likely to engage in all elements of the IS plans. The centralized governance of hospitals that belong to a health system could explain the reason behind this finding. Finally, we did not find any 
significant relationship between bed size and elements of IS plans except 'resolving integration issues', where we found that bed size was significantly associated with lower likelihood of resolving integration issues.

Our study presents some strengths. First, using contingency theory as a framework, this study is one of the first papers to explore the phenomenon of technology adoption derived from organizational structure. Second, it relies on a validated and widely used HIMSS analytics database that captures hospitals' Strategic Information Systems Planning; thus adding reliability to our findings. Third, we employed rigorous statistical analysis methods suitable for our study population. In addition, we used multiple attributes of IS planning instead of a single dimension thus providing a more comprehensive measurement of IS planning. Finally, we aggregated the scores on the various dimensions to generate a summated score to provide a homogenous measure of IS planning; also providing greater complexity to our analysis.

Despite the aforementioned strengths, our study is not without limitations. This study relies on secondary data which limits us to only five components of IS plans. Also, our study relies on cross-sectional data and reveals more of an association rather than the cause. Finally, the study does not examine other factors that may have been pertinent to SISP such as the presence of a robust telehealth program.

Further research can investigate the same phenomenon using longitudinal data and can explore relationships between SISP and organizational performance such as financial and quality outcomes (Salge, Kohli, \& Barrett, 2015; Upadhyay \& Smith, 2016). Additionally, future studies should examine how other organizational characteristics may influence strategic information systems planning. To do so, a qualitative approach may be beneficial. While our findings are not generalizable, they do offer extensive information to hospitals due to the breadth and depth of the sample of hospitals utilized in these databases.

This study provides several implications for policy makers and practitioners. First, policymakers will appreciate how difference in organizational characteristics can influence Strategic Information Systems Planning. Instead of having a "one size fits all" approach to technology adoption, they could develop policy exceptions for hospitals that do not have the advantages of being system affiliated, which are for-profit or are located in an urban area. Second, our research informs practice managers and consultants about organizational characteristics that they should consider when making strategic business decisions about improving healthcare quality and efficiency through Strategic Information Systems Planning. The characteristics of their organizations may hinder or support their Strategic Information Systems Planning. Third, findings from this research will help 
ensure managers and decision makers are keenly aware of challenges and opportunities that exist within their organization to assist them in future decision making regarding technology adoption. This is especially pertinent for healthcare systems as they continue to explore information systems as possible solutions for existing challenges such as improvement in healthcare quality and safety including better patient flow and discharge planning (IOM, 2000; Johnson \& Capasso, 2012). An understanding of the relationship between organizational characteristics and SISP can support hospitals' objectives of delivering high quality healthcare.

\section{Conclusion}

Hospitals that engage in Strategic Information Systems Planning (SISP) have the potential to optimally utilize Information Systems to improve quality of healthcare and outcomes. Hospital performance measures are increasingly being attached to financial reimbursements, which affects hospital performance and urges hospital managers to be mindful of their resource investments. With an extensive financial commitment required for full Information Systems adoption, engaging in strategic planning for Information Systems would be beneficial in aligning organizational characetristics to SISP. A careful strategic planning would assist managers in allocating sufficient resources to Information Systems adoption. Furthermore, healthcare organizations and hospital managers must strive to deliver high quality care to their patients. Findings from our study would assist them in ensuring their IT investments are positioned for successful returns on both the quality and financial side.

\section{References:}

1. Abramson, E. L., McGinnis, S., Edwards, A., Maniccia, D. M., Moore, J., \& Kaushal, R. (2012). Electronic health record adoption and health information exchange among hospitals in New York State. Journal of Evaluation in Clinical Practice. 18 (6): 1156-1162.

2. Adler-Milstein, J., Kvedar, J., \& Bates, D. W. (2014). Telehealth among US hospitals: several factors, including state reimbursement and licensure policies, influence adoption. Health Affairs 33(2): 207215.

3. Agarwal, R., Gao, G., DesRoches, C., \& Jha, A. K. (2010). Research commentary-The digital transformation of healthcare: current status and the road ahead. Information Systems Research 21(4): 796-809.

4. Amrollahi, A., Ghapanchi, A. H., \& Talaei-Khoei, A. (2013). A Systematic Literature Review on Strategic Information Systems Planning: Insights from the Past Decade. Pacific Asia Journal of the Association for Information Systems. 5 (2): 4. 
5. Bode, I., \& Maerker, M. (2014). Management in medicine or medics in management? The changing role of doctors in German hospitals. International Journal of Public Sector Management, 27(5), 395-405.

6. Bowman, S. (2013). Impact of electronic health record systems on information integrity: quality and safety implications. Perspectives in Health Information Management, 10(Fall).

7. Buntin, M. B., Burke, M. F., Hoaglin, M. C., \& Blumenthal, D. (2011). The benefits of health information technology: a review of the recent literature shows predominantly positive results. Health Affairs 30 (3): 464-471.

8. Chaudhry, B., Wang, J., Wu, S., Maglione, M., Mojica, W., Roth, E., Shekelle, P. G. (2006). Systematic review: impact of health information technology on quality, efficiency, and costs of medical care. Annals of Internal Medicine 144 (10):742-752.

9. DesRoches, C. M., Charles, D., Furukawa, M. F., Joshi, M. S., Kralovec, P., Mostashari, F., Jha, A. K. (2013). Adoption of electronic health records grows rapidly, but fewer than half of US hospitals had at least a basic system in 2012. Health Affairs, 10-1377 /hlthaff.2013.0308.

10. Diana, M. L., Harle, C. A., Huerta, T. R., Ford, E. W., \& Menachemi, N. (2014). Hospital characteristics associated with achievement of meaningful use. Journal of Healthcare Management 59 (4): 272-284.

11. Donaldson, L. (2001). The contingency theory of organizations: Sage.

12. Drazin, R., \& Van de Ven, A. H. (1985). Alternative forms of fit in contingency theory. Administrative Science Quarterly, 514-539.

13. Fisher, J. G. (1998). Contingency theory, management control systems and firm outcomes: past results and future directions. Behavioral research in Accounting 10: 47.

14. Ford, E. W., Menachemi, N., Huerta, T. R., \& Yu, F. (2010). Hospital IT adoption strategies associated with implementation success: implications for achieving meaningful use. Journal of Healthcare Management 55(3): 175-189.

15. Hibbard, J. H., \& Greene, J. (2013). What the evidence shows about patient activation: better health outcomes and care experiences; fewer data on costs. Health Affairs, 32(2), 207-214.

16. HITECH Act Enforcement Interim Final Rule. (2009, December 24). Retrieved from https://www.hhs.gov/hipaa/for-professionals/specialtopics/HITECH-act-enforcement-interim-final$\underline{\text { rule/index.html?language }=\text { esHouser, }}$ 
17. Holup, A. A., Dobbs, D., Meng, H., \& Hyer, K. (2013). Facility characteristics associated with the use of electronic health records in residential care facilities. Journal of the American Medical Informatics Association, 20(4), 787-791.

18. Hoque, M. R., Hossin, M. E., \& Khan, W. (2016). Strategic Information Systems Planning (SISP) Practices In Health Care Sectors of Bangladesh. European Scientific Journal, ESJ, 12(6).

19. Houser, S. H. and L. A. Johnson. (2008). Perceptions regarding electronic health record implementation among health information management professionals in Alabama: a statewide survey and analysis. Perspectives in Health Information Management, 5(6): 1.

20. Institute of Medicine. (2000). To err is human: Building a safer health system. Washington, DC: National Academies Press.

21. Johnson, M. \& Capasso, V. 2012. Improving patient flow through a better discharge process. Journal of Healthcare Management 57 (2): 89-93.

22. Lammers, E. J., Adler-Milstein, J., \& Kocher, K. E. (2014). Does health information exchange reduce redundant imaging? Evidence from emergency departments. Medical care, 52(3), 227-234.

23. Lee, T., Ghapanchi, A. H., Talaei-Khoei, A., \& Ray, P. (2015). Strategic Information System Planning in Healthcare Organizations. Journal of Organizational and End User Computing (JOEUC), 27 (2): $1-31$.

24. Menachemi, Shin, D. Y., Ford, E. W., \& Yu, F. (2011). Environmental factors and health information technology management strategy. Health Care Management Review, 36 (3): 275285.

25. Miller, A. R., \& Tucker, C. (2014). Health information exchange, system size and information silos. Journal of Health Economics, 33, $28-42$.

26. Najaftorkaman, M., Ghapanchi, A. H., Talaei-Khoei, A., \& Ray, P. (2015). A taxonomy of antecedents to user adoption of health information systems: A synthesis of thirty years of research. Journal of the Association for Information Science and Technology, 66(3), 576-598.

27. Otley, D. T. (1980). The contingency theory of management accounting: achievement and prognosis. Accounting, Organizations and Society 5(4): 413-428.

28. Patient Protection and Affordable Care Act (PPACA). (2010). Pub. L. No. 111-148,124 Stat.119.

29. Pai, F. Y., \& Huang, K. I. (2011). Applying the technology acceptance model to the introduction of healthcare information 
systems. Technological Forecasting and Social Change 78 (4): 650660.

30. Pham, J. C., Aswani, M. S., Rosen, M., Lee, H., Huddle, M., Weeks, K., \& Pronovost, P. J. (2012). Reducing medical errors and adverse events. Annual Review of Medicine 63, 447-463.

31. Radley, D. C., Wasserman, M. R., Olsho, L. E., Shoemaker, S. J., Spranca, M. D., \& Bradshaw, B. (2013). Reduction in medication errors in hospitals due to adoption of computerized provider order entry systems. Journal of the American Medical Informatics Association, 20(3), 470-476.

32. Salge, T. O., Kohli, R., \& Barrett, M. (2015). Investing In Information Systems: On The Behavioral And Institutional Search Mechanisms Underpinning Hospitals' IS Investment Decisions. Management Information Systems Quarterly, 39(1).

33. Sittig, D. F., \& Singh, H. (2010). A new sociotechnical model for studying health information technology in complex adaptive healthcare systems. Quality and Safety in Health Care, 19 (Suppl 3), i68-i74.

34. StataCorp, L. P. (2015). College Station, TX. STATA® Software Version, 13.

35. Upadhyay, S., Sen, B., \& Smith, D. (2015). The cash conversion cycle and profitability: A study of hospitals in the state of Washington. Journal of Health Care Finance, 41(4).

36. White, C., \& Wu, V. Y. (2014). How do hospitals cope with sustained slow growth in Medicare prices?.Health services research, 49(1), 11-31.

37. Winter, A., Brigl, B., Buchauer, A., Dujat, C., Gräber, S., Hasselbring, W., Kock, I. (2000). Purpose and structure of strategic plans for information management in hospitals. Studies in Health Technology and Informatics 77, 880-884.

38. Zona, F., Zattoni, A., \& Minichilli, A. (2013). A contingency model of boards of directors and firm innovation: The moderating role of firm size. British Journal of Management, 24(3), 299-315.

39. Zhang, N. J., Seblega, B., Wan, T., Unruh, L., Agiro, A., \& Miao, L. (2013). Health information technology adoption in US acute care hospitals. Journal of Medical Systems 37 (2): 1-9. 